\title{
The effect of a new setting agent for wool
}

\begin{tabular}{|l|l|}
\hline 著者 & Mor i Masukuni, Nat sudai ra M t suo \\
\hline $\begin{array}{l}\text { j our nal or } \\
\text { publ i cat i on ti t l e }\end{array}$ & Fi ber s and Pol yner s \\
\hline vol une & 10 \\
\hline number & 2 \\
\hline page r ange & $185-192$ \\
\hline year & 2009- O4 01 \\
\hline URL & ht t p: //hdl . handl e. net /2297/18156 \\
\hline
\end{tabular}




\title{
The Effect of a New Setting Agent for Wool
}

\author{
Masukuni Mori ${ }^{1}$ and Mitsuo Matsudaira* \\ ${ }^{1}$ Mori Consultant Engineering Office, Kaimei, Ichinomiya City, 494-0001, Japan \\ * Faculty of Education, Kanazawa University, Kakuma, Kanazawa City, 920-1192, Japan
}

(Received )

\begin{abstract}
Pleated wool fabrics were prepared by the treatment with ethylenediamine (EDA) at $90^{\circ} \mathrm{C}$ for $30 \mathrm{~min}$. The degree of set, tensile property and dyeing of the treated fabrics have been discussed in relation to the concentration of EDA in the treatment system. No significant decreases in tensile strength and elongation, and great increases of exhaustion of synthetic and natural dyes were observed. Pleat and flat set were successfully attained in a wide range of the concentration of EDA. Excellent dyeability and setability of the fabrics obtained were considered to be associated with the existence of new cross-link, $\beta$ - $N$-(2-aminoethyl)alanino- $\beta$-aminoalanine and the pendant group, $\beta$ - $N$-(2-aminoethyl) aminoalanine produced by the reaction of EDA with dehydroalanine intermediate.
\end{abstract}

Keywords: Wool fabric, Ethylenediamine, Pleat and flat set, Alkali and urea-bisulfite solubility, Cross-linking, Yellowing, Dyeing, Color fastness, Tensile strength and elongation.

\section{Introduction}

Wool fiber and fabrics have many advantages on clothing and physiological properties such as water absorptivity, water repellency, warm keeping and heat insulating ability as compared with those of polyester. The elastic and crease recovery properties of wool fibers add further important values on wool clothes. However, the creases on wool fabrics produced by using a heating iron easily disappear after wearing and exposing in wet or even in a humid condition. At present, permanent pleat and flat set have been performed by either a chemical setting using reducing agents such as thioglycolic acid and cysteine at an alkaline $\mathrm{pH}$ or by a physical means as thermal crabbing. Creases of trousers and pleat skirts are introduced by using a technique in the former and flat set of plane fabrics in the latter. In principle, the setting mechanism is due to the so-called thiol/disulfide ( $\mathrm{SH} / \mathrm{SS}$ ) interchange reactions between the side chains of cysteine and cystine residues in wool keratin proteins, which lead to a stable conformation through the internal stress relaxation 
of wool fiber [1-3]. The SH/SS interchange reaction is reversible, and thus undesirable crease and/or rope mark occur sometimes.

With respect to the setting in higher extension state, the mechanism for permanent set in boiling water has been proposed by Robson et al. [4]. They concluded that the enhanced stabilization of protein conformation is due to the formation of stable cross-links such as lanthionine and lysinoalanine linkages. Arai et al. studied about the setting in boiling water at $40 \%$ extension state on the basis of the number of the formation of new intermolecular cross-links, which was determined by applying a rubber elasticity theory to the swollen fibers for setting wool at varying the time of set and concluded that the extension set was attained by stabilization of the conformation of non-helical end regions of the intermediate filament proteins by lanthionine and lysinoalanine cross-linkages [5].

In this paper, the bifunctional reagent of ethylenediamine (EDA) was proposed as a new setting agent of wool. The effect of permanent crease treatment on permanency was discussed in relation to crease finish and the cross-linking reaction mechanism was also proposed. Alkali or urea-bisulfite solubility, yellowing, dyeability and mechanical properties have been widely discussed for the treated samples obtained at a variety of the degrees of set.

\section{Experimental}

\section{Materials}

Ethylenediamine (EDA) and methylene blue were from Wako Chemical Co. (Japan).The dyes used were commercial products with C.I. number. Two kinds of fabrics were used as the samples of finishing and dyeing.

Sample A was 2/2-twill fabric made of 2/60 Merino wool (100\%) yarn in warp and weft and weighed $120 \mathrm{~g} / \mathrm{m}^{2}$, and Sample B was 2/2-twill made of 1/40 New Zealand Corriedal wool (100\%) yarn in warp and weft and $85 \mathrm{~g} / \mathrm{m}^{2}$. A clear finishing was performed for all of the fabrics used as samples. Here, Sample B was used only for setting experiments and Sample A was used for all experiments described in the present paper.

\section{Setting Method}

A device for a pleat set experiment of wool fabric is shown in Figure 1. A fold fabric in half was placed between two square tiles of $10 \mathrm{~cm} \times 10 \mathrm{~cm}$ so as to make coincide the folding line with the sides of the two tiles is shown in Figure 1(a). The side view of the tiles and the fold line of the fabric with a rectangular shape of $10 \mathrm{~cm} \times 20 \mathrm{~cm}$ is shown in Figure 
1(b). Here, two kinds of rectangular pieces with different directions of warp and weft were prepared. The tiles fasten in a cross shape by cotton ropes were dipped in a solution containing EDA at the concentrations of 0, 1, 3, 6,10 and 20\% (o.w.f.) in liquor to wool ratio of 50:1. The solution temperature was raised from room temperature to $90^{\circ} \mathrm{C}$ in 20 min and further $10 \mathrm{~min}$ was maintained for setting treatment. The treated sample was cooled in cold water, and removed from the setting flame, washed with cold water, and then dried for $5 \mathrm{~min}$ at $110^{\circ} \mathrm{C}$. The set fabrics obtained were subjected to durability tests as the sample just after setting.

$$
\text { (insert Figures 1(a) and 1(b)) }
$$

\section{Durability}

Durability tests of the pleated set fabrics were carried out after the treatment by three different process: (1) set fabric washed with cold water and dried for $5 \mathrm{~min}$ at $110^{\circ} \mathrm{C}$ as described above, the so-called "just after setting process", (2) set fabric washed with cold water was dipped in a solution containing $0.1 \%$ surfactant at $60^{\circ} \mathrm{C}$ for $30 \mathrm{~min}$ and dried for $24 \mathrm{~h}$ on a wire net at an aerated condition, which was denoted as "soaking process", and (3) set fabric washed with cold water was further washed by using a machine washer (IWTO $\mathrm{TM}-315 \mathrm{~A}$ ) at the temperature of $40 \pm 3^{\circ} \mathrm{C}$ for $15 \mathrm{~min}$, rinsed, and repeated 5 times this process and then finally dried for $24 \mathrm{~h}$ on the wire net, which was denoted as "washing process". These treated samples were subjected to the measurement of bent angle.

Durability of set was judged on the basis of a standard if the bent angle was less than 90 degree and the pleated line was clearly recognized. Measurement of bent angle of pleated fabrics was performed according to the method of JIS-L-1060 A2. Five yarns sized $20 \mathrm{~mm}$ in left and right from the pleated point, that is, $40 \mathrm{~mm}$ bent yarns were taken out from fabric, and dipped in a $1.0 \mathrm{~g} / 1$ nonionic surfactant solution $(100 \mathrm{ml})$ at $25 \pm 2{ }^{\circ} \mathrm{C}$ for $2 \mathrm{~min}$ in a Petri dish. The bent angle of the yarn was measured by a circular protractor from the outside of the dish and calculated according to the equation (1). The average value of ten measurements was shown by integer. In the present study, the degree of set was defined by equation (1):

$$
\text { Bent angle }=(\theta / 180) \times 100
$$

where $\theta$ is the measured angle in degree.

\section{Tensile Strength}


The tensile strength measurements for untreated and treated samples just after setting were carried out by applying the Labeled strip method (JIS-L-1096 A). A rectangular sample of $50 \mathrm{~mm}$ in width and $200 \mathrm{~mm}$ in length was stretched along the length by a constant speed of $10 \mathrm{~mm} / \mathrm{min}$. The average value of the tensile strengths obtained from 5 measurements was taken.

\section{Alkali and urea-bisulfite solubility}

Alkali solubility (JIS-L-1081): about $1 \mathrm{~g}$ of absolutely dried sample was weighed and dipped in a $0.1 \mathrm{mo} / 1$ solution of sodium hydroxide containing $100 \mathrm{ml}$ in a flask at $65 \pm$ $0.5^{\circ} \mathrm{C}$ for $1 \mathrm{~h}$. Then, the solution was filtered under suction and the residue was washed 6 times with distilled water at $40^{\circ} \mathrm{C}$, neutralized with an acetic acid solution, washed 6 times with water and weighed after absolute drying. Alkali solubility was calculated by equation 2 and the average value of twice was taken.

$$
S=100\left(W_{d}-W_{r}\right) / W_{d}
$$

where $S$ is the alkali solubility, $W_{d}$ is the absolutely dried mass of the sample in grams, and $W_{r}$ is the absolutely dried mass of the residue in grams.

Urea-bisulfite solubility (JIS-L-1081): an aqueous urea solution was prepared by dissolving $50 \mathrm{~g}$ of urea into boiling water and subsequently $3 \mathrm{~g}$ of sodium bisulfite was added to the solution, and after cooling, $2 \mathrm{ml}$ of a $5 \mathrm{~mol} / 1$ sodium hydroxide solution was further added, and then diluted exactly to $100 \mathrm{ml}$ by distilled water to obtain the urea-bisulfite (UB) solution. About $1 \mathrm{~g}$ of absolutely dried sample was weighed and put into UB solution in a stoppered flask and the flask was shaken for about $5 \mathrm{sec}$ in every 15 $\min$ at $65 \pm 0.5^{\circ} \mathrm{C}$ for $1 \mathrm{~h}$. The solution was filtered under suction for $60 \mathrm{~min}$ and the residue obtained was washed 3 times with $10 \mathrm{ml}$ of UB solution and then further washed 6 times with distilled water. The residue in a crucible was dried at $105 \pm 2{ }^{\circ} \mathrm{C}$ and weighed. The UB solubility was calculated by equation (3) and the average value of twice was taken.

$$
S_{u}=100\left(W_{d}-W_{r}\right) / W_{d}
$$

where $S_{u}$ is the UB solubility, $W_{d}$ is the absolutely dried mass of the sample in grams, and $W_{r}$ is the absolutely dried mass of the residue in grams.

\section{Dyeing}


Different types of 8 synthetic dyes designated as (a) to (h), which are shown by C.I. number (type of dye) were used. The composition of dyeing solution was represented by $\%$ (o.w.f.), and the numbers in parenthesis denote a range of solution $\mathrm{pH}$. Temperature was raised by $1.5^{\circ} \mathrm{C} / \mathrm{min}$ to the highest dyeing temperature at $100^{\circ} \mathrm{C}$ and maintained for $40 \mathrm{~min}$, and dyed fabric was dried after washing thoroughly with water except for any other specified. Dyeing condition for each dye was as follows: (a) C.I. Acid Red 106 (leveling type); $2.0 \%$ dye and $2.0 \%$ formic acid (85\% w/v), (3.5-4.0), (b) C.I. Acid Green 25 (milling type); $2.0 \%$ dye and $2.0 \%$ acetic acid (99\% w/v), (4.0-4.5), (c) C.I. Acid Blue 185 (phthalocyanine dye); 3.0\% dye and 3.0\% formic acid (85\% w/v), (3.0), (d) C.I. Acid Black 207(1:2 metal complex dye); $2.0 \%$ dye and $0.5 \%$ acetic acid $(99 \% \mathrm{w} / \mathrm{v}),(4.5-5.0)$, (e) C.I. Neolan Black P (1: 1 metal complex dye); $2.0 \%$ dye and $4.0 \%$ sulfuric acid $(99 \% \mathrm{w} / \mathrm{v})$, (2.0), (f) C.I. Mordant Black 11 (acid mordant dye); $3.0 \%$ dye and $2.0 \%$ acetic acid (99\% $\mathrm{w} / \mathrm{v}),(4.0-4.5) ; 100^{\circ} \mathrm{C}$ for $30 \mathrm{~min}$ and then added $0.4 \%(\mathrm{w} / \mathrm{v})$ sodium dichromate and further dyed for $30 \mathrm{~min}$, (g) C.I. Reactive Black 5(reactive dye); $5.0 \%$ dye and $2.0 \%$ acetic acid $(99 \% \mathrm{w} / \mathrm{v}),(4.0-4.5) ; 100^{\circ} \mathrm{C}$ for $40 \mathrm{~min}$. Dyed fabric was washed in hot water at $60^{\circ} \mathrm{C}$ for $5 \mathrm{~min}$, and further washed thoroughly with cold water and dried, (h) C.I. Basic Violet 11(basic dye); $2.0 \%$ dye and 2.0\% acetic acid (99\% w/v), (4.0-4.5).

Different kinds of 5 natural dyes designated as (a) to (e) were used. The concentration of each dye was $20 \%$ (o.w.f.) and the solution $\mathrm{pH}$ was 6.5. Temperature was raised by $2^{\circ} \mathrm{C} / \mathrm{min}$ from $50^{\circ} \mathrm{C}$ to the highest temperature of $100^{\circ} \mathrm{C}$, and maintained for $30 \mathrm{~min}$ except for any other specified. Dyed fabrics were further treated by the mordant of copper (II) sulfate pentahydrate and ferric nitrate at a range of $\mathrm{pH} 4.5$ to 5.0 to improve color intensity and color fastness. The natural dyes used were as follows: (a) Persimmon; temperature was raised after dipping for $10 \mathrm{~min}$ in the dyeing solution at room temperature, (b) Catechu (bark of a tree), (c) Pomegranate (seed of a plant), (d) Myrabolams (leaf of a plant), (e) Lac-dye (parasite of a plant).

\section{Staining Treatment}

A methylene blue staining reagent was prepared as follows: $1.279 \mathrm{~g}$ of methylene blue and $6.81 \mathrm{~g}$ of potassium hydrogen phosphate were dissolved in distilled water, and $29.63 \mathrm{ml}$ of a $1 \mathrm{~mol} / \mathrm{l}$ solution of potassium hydroxide was added, and then diluted the mixed solution exactly to $1000 \mathrm{ml}$ by distilled water. About $1 \mathrm{~g}$ of wool fabric was dipped in 0.1 mol/1 solution of hydrochloric acid for $1 \mathrm{~h}$, then washed with water and followed by immersing into $200 \mathrm{ml}$ of the methylene blue reagent in a stoppered flask for $24 \mathrm{~h}$, washing with water and then drying, and finally the color of staining fabric was measured and the 
stain was evaluated.

\section{Calorimetric Measurement}

Color of dyeing sample was measured by a spectro-colorimeter, Minolta CM-3600D equipped with a light source of D65, and visual field of 10 degrees. Color yield was obtained as the ratio of reflectance at maximum absorption wave length using $K / S$ value of Kubelka-Munk equation. The values of $L^{*}, a^{*}, b^{*}$ of CIELAB color expression method were obtained for dyed fabrics and $L^{*}$ value was used for indication of color yield.

\section{Color Fastness}

Color fastness test (JIS-L-0845) was conducted by using hot water as the so-called potting fastness. To evaluate color fastness of wool fabric, $100 \%$ cotton white fabric was used as an adjacent fabric. They were dipped in $70 \pm 2^{\circ} \mathrm{C}$ for $30 \mathrm{~min}$ and the color change was evaluated. Color fastness test to daylight using the $3^{\text {rd }}$ exposure (JIS-L-0841) and color fastness test to rubbing (JIS-L-0849) in both dry and wet conditions were also performed.

\section{Results and Discussion}

\section{Relationship between EDA Concentration and Degree of Set}

Relationships between EDA concentration and the degree of set are shown in Fig. 2. The degree of set for the control sample prepared by the absence of EDA shows $82 \%$ for the sample just after setting, $65 \%$ for the sample after soaking and only $30 \%$ for the sample after washing, respectively. On the contrary, the values obtained for the samples prepared in the presence of EDA are significant. As the concentration of EDA increases, the degree of set increases markedly, and tends to saturate at nearly $95 \%$ or more, and $85 \%$ when the concentration is about $6 \%$ for the sample even after washing.

(Insert Figures 2 and 3)

The appearances of the set fabrics are shown in Fig. 3. For the samples obtained at the concentrations of EDA less than $6 \%$, the edge of the fabrics corresponding to samples (b) to (d) curls up, but that to the samples (e) and (f) obtained at the concentrations more than $10 \%$ does not, and the pleats are clearly sustained after soaking and an excellent flat set can be also recognized.

\section{Tensile Strength and Yellowing of Set Fabric}


The relationship between the tensile strength and the concentration of EDA is shown in Figure 4 . The strength decreases rapidly with the increase of the concentration of EDA in a lower concentration range below 3\% and tends to decrease slowly at higher concentrations, and maintains a value corresponding to about $91 \%$ level as compared to that of the control sample. The decrease in the elongation is only about $2 \%$ at the highest concentration of EDA examined as shown in Figure 5. This indicates that the damage due to the present set treatment is not so large as to affect on the practical use.

The relation between the degree of yellowing, $L^{*}$ and the concentration of EDA is also shown in Figure 4. A similar tendency to the curve of tensile strength can be observed. This suggests that the yellowing proceeds in parallel to the extent of the reactions presumed as a function of tensile strength during the treatment. The degree of yellowing for the sample treated with $10 \%$ of EDA was estimated to be lowered only about $2.2 \%$ as compared with that of untreated fabric.

(insert Figures 4 and 5)

\section{K/S -value for Synthetic Dyes}

Relationships between the concentration of EDA and $K / S$ value for dyeing samples are shown in Figures 6 and 7. The $K / S$ value indexing color intensity for all of the dyes tested increase remarkably even in a range of lower concentration of EDA below about $2 \%$, and tend to level off except for phthalocyanine dye resulting in a decrease with increasing the concentration of EDA. The color intensity of acid dyes is significantly improved by the setting treatment, i.e., the $K / S$ ratios of $20 \%$ EDA to $0 \%$ EDA increase in the range of 1.2 to 2.1 for synthetic dyes examined. The behavior characteristic in acid dye is probably associated with the incorporation of EDA molecule into the keratin protein chains, suggesting an increase of amino groups in the initial reaction step, while a slow down of the incorporation of amino groups in the latter step of the reaction. The leveling off values in $K / S$ value at the higher concentration of EDA are decreased in the order 1,2-metal complex $>>$ milling $>$ leveling $>>$ basic. As shown in this order, the retarding or inhibiting the dyeing of basic dye may be caused by the increase in the content of amino groups.

(insert Figures 6 and 7)

\section{K/S-value for Natural Dyes}

As shown in Figure 8, approximately linear relationships can be observed between the $K / S$-value and the concentration of EDA for dyeing of various natural dyes. The increase in 
the $K / S$ ratio of $20 \%$ EDA to $0 \%$ EDA reaches to the range from 1.8 to 5.2. Dyeing mechanism is clearly different between the synthetic and natural dyes. The exhaustion of natural dyes is likely to be dependent on the structural change of wool proteins brought about by the cross-linking reaction of EDA, which may induce an open structure in the proteins.

\section{(insert Figure 8)}

\section{Color Fastness}

The results of color fastness are shown in Table 1. Color fastness improved very much as compared with untreated fabrics. The improvement was especially large for potting fastness and wet rubbing fastness of natural dyes. This phenomenon can probably be explained by the increase of dyeing site according to the incorporation of functional groups by the treatment. It has been reported that the reactive intermediate dehydroalanine residue will react with alkyl amines to form $\beta$-N-alkyl aminoalanine [6], and the introduction of these basic groups into wool fiber increases the affinity toward acid dyes [7]. It is appropriate to consider that from the dyeing behavior of EDA-treated wool fabric, a large amount of basic amino groups are linked in keratin chains via the reaction of dehydroalanine residue with EDA.

\section{(insert Table 1)}

\section{Alkali and UB solubility}

The alkali solubility, $S$ represented by equation (2) is the index of the amount of intermolecular disulfide (SS) cross-links, since all of the SS bonds are transformed to lanthionine linkage and the protein chains with intramolecular SS bond can be dissolved by the treatment with an aqueous alkaline solution containing urea, while the protein chains cross-linked by the intermolecular linkage remains as insoluble residues. About 3\% larger value of alkali solubility, $S$, is obtained for the treated wool with $20 \%$ of EDA as compared with untreated one. This means that some amount of intermolecular SS bonds was decreased by the EDA treatment, even if new intermolecular cross-links were introduced by the present EDA treatment.

\section{(insert Table 2)}

The UB solubility, $S_{u}$ represented by equation (3) is the index of the total amount of SS bonds in wool, since the solubility test solution contains urea and sodium bisulfite, which reacts with SS bond as a reducing agent to form bunte salt and sulfhydryl (SH) group and all of the SS bonds are reduced under the test conditions. As compared with both values of $S$ and $S_{u}$ for untreated wool in Table 2, the latter is larger than the former, which means a 
larger percentage ratio of the insoluble residue in the former than in the latter, suggesting the results obtained are very reasonable from the above consideration.

The $S_{u}$-value obtained for the EDA-treated fabric at the concentration of $20 \%$ is strikingly small as compared with that of untreated wool. This clearly indicates that a comparatively large number of new intermolecular cross-links were introduced during the treatment with a relatively higher concentration of EDA. Although an exact interpretation of the difference between the values of $S$ and $S_{u}$ for EDA-treated fabric is difficult at present, it could be assumed primarily that in an alkaline medium, the new cross-links introduced by EDA-treatment are related to the reactions with a reactive SS group of cystine residue in the keratin protein [4, 8-12]. Firstly, when the intermolecular linkages of SS groups are transformed into the same amount of new intermolecular cross-links, the $S$-value will be equal to 17.5 of the corresponding value of untreated wool. Secondary, when the intermolecular linkages of a part of SS groups are changed into new intramolecular linkages, the S-value of 20.4 will be explicable, but we could not explain the exceedingly small $S_{u}$-value. Thirdly, when the intermolecular linkages of a greater part of SS groups are changed into new cross-linkages in a proper ratio of the inter- and intra-molecular linkages, a possible explanation will be provided. Further study is needed to determine the ratio of inter- to intra- molecular linkages.

\section{Color Intensity of Fabrics Stained with Methylene Blue}

The color intensity in terms of $K / S$-value for the methylene blue staining fabrics, which have been treated with various concentrations of EDA is shown in Table 3. The values increase with the increase of the concentration of EDA. A similar consideration to the exhaustion of natural dyes may be applied to the increment in the stain of methylene blue. The open structure of cross-linked network produced by the treatment with EDA is responsible for the uptake of the basic dye.

\section{(insert Table 3)}

\section{Reaction Mechanism}

The self-crosslinking reactions occurring in wool fiber by the action of alkali and boiling water were reported from many workers and have been reviewed by Ziegler [8]. The same author demonstrated that the setting of wool with alkaline treatment results in the formation of lysinoalanine and the mechanism of the formation is due to DHAL as the intermediate [9, 10]. Afterwards, Asquith et al. [11, 12] showed that low molecular weight aliphatic amines in alkaline media results in the incorporation into wool fibers according to the similar mechanism via DHAL residue and also showed that these treatments have some enhanced 
effects of exhaustion and fixation of dyes [12]. It can be expected that in our present study using diamine a similar mechanism of the formation of cross-links is through DHAL as demonstrated by Asquith et al [11]. The change in dyeability of wool has been considered to be due to the introduction of basic side chain. The reactions occurring in wool fibers immersed in an aqueous solution containing EDA at $90^{\circ} \mathrm{C}$ will be proposed on the basis of the knowledge from the previously publishing papers and our results in the present study on alkali and UB solubility.

When wool fiber is treated in boiling water, cystine residue (KSSK) transforms into dehydroalanine (DHAL) and perthiocysteine (PTC) as equation (4) and PTC is hydrolyzed to form cysteine residue (KSH)

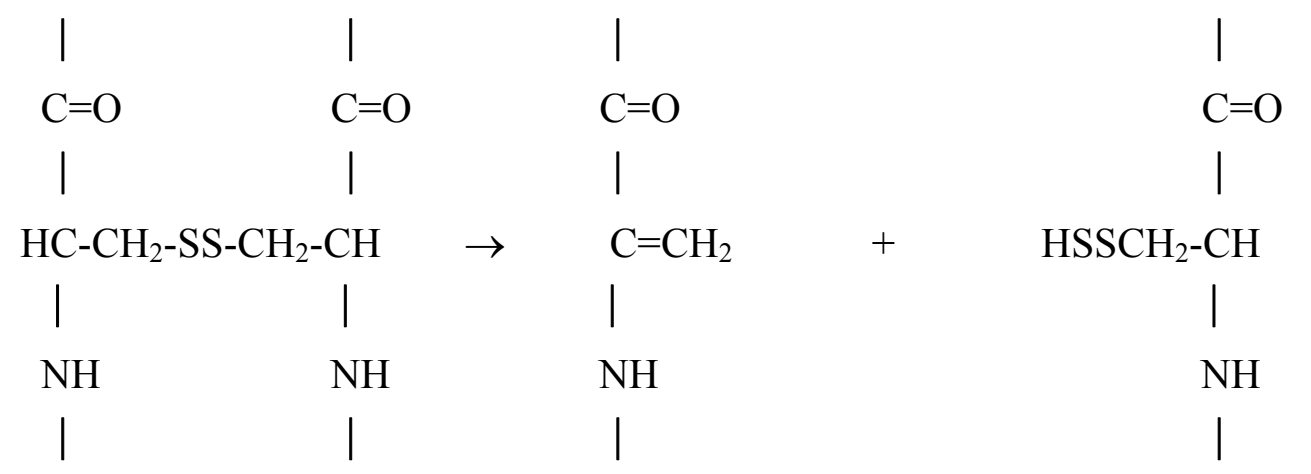

KSSK DHAL PTC

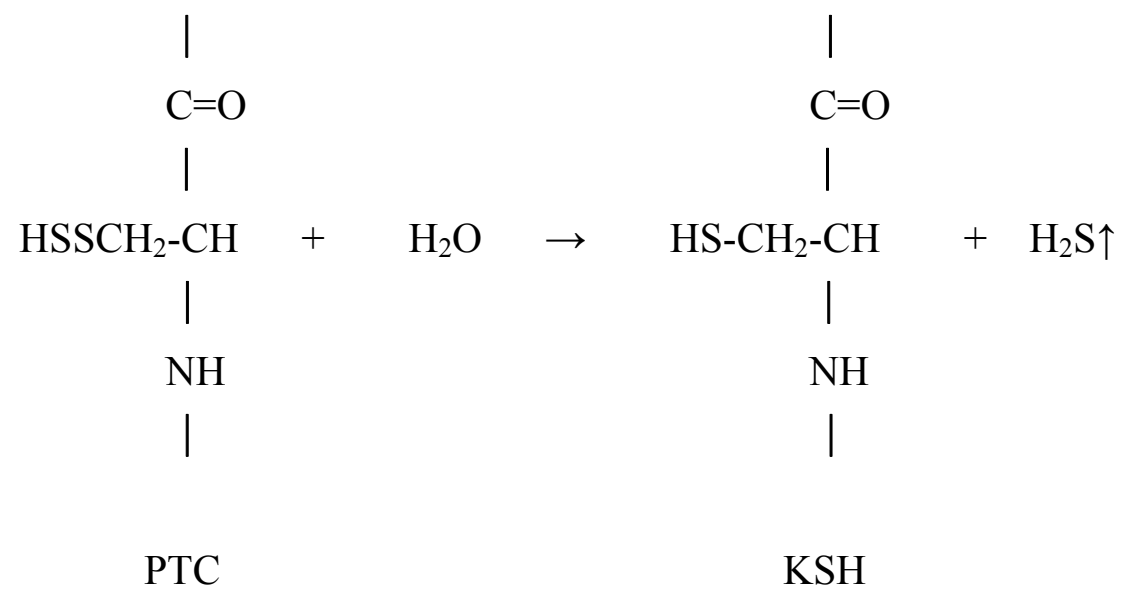

according to equation (5). Furthermore, DHAL reacts with $\mathrm{KSH}$ to form lanthionine (LAN) cross-link according to equation (6). 


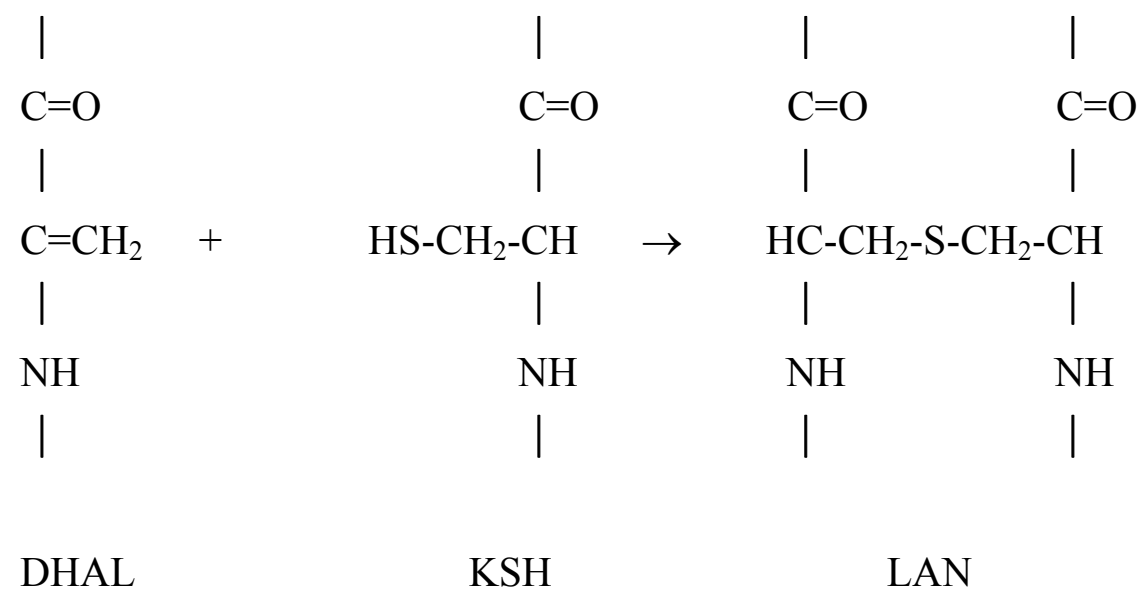

Here, it is well known that DHAL residue reacts with lysine (Lys) residue to generate lysinoalanine (LAL) cross-link according to equation $(7)[8,11]$.

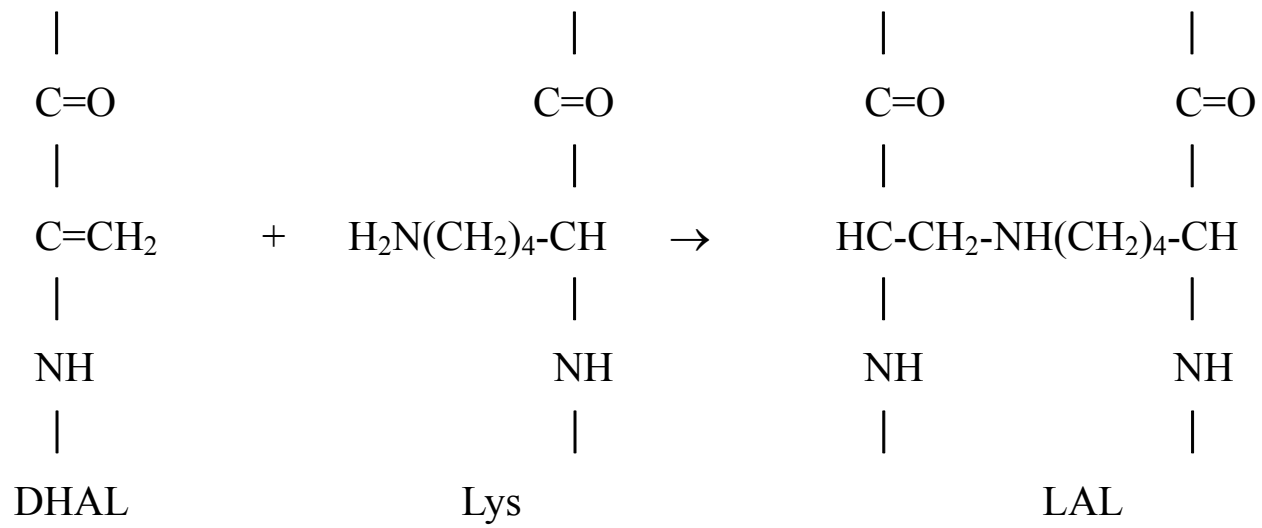

As DHAL reacts with free amino group easily, similar reaction may occur with ethylenediamine (EDA), which exists a lot in the solution to generate $\beta$ - $N$-(2-aminoethyl)alanino- $\beta$-aminoalanine cross-link (AEAAAL) through equation (8).

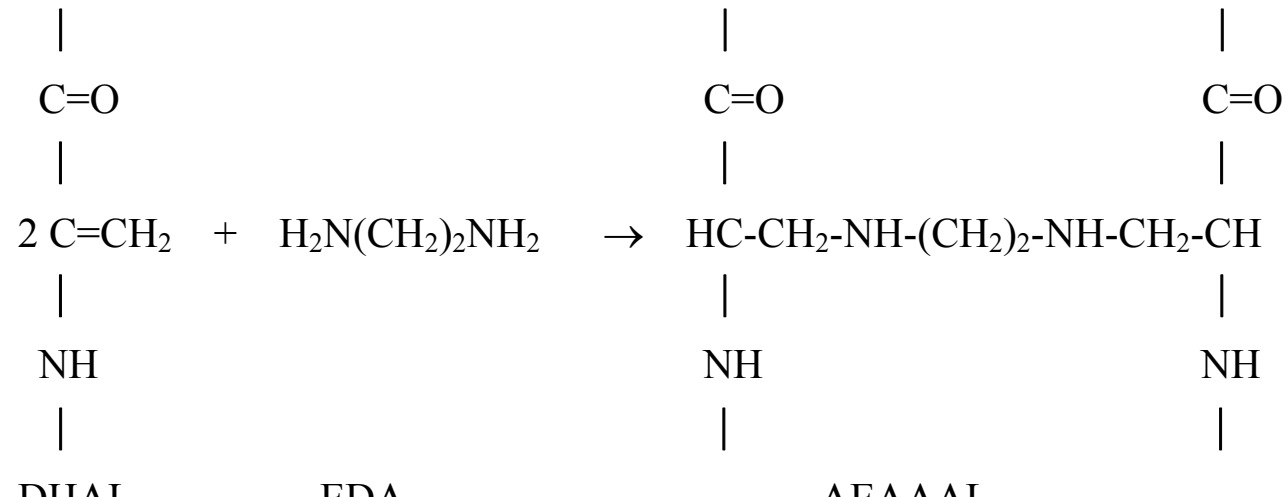

If the concentration of EDA is lower, the reaction according to equation (6) may occur 
dominantly.

Absorption of basic dye is slightly increased when the concentration of EDA was lower than $5 \%$ as shown in Figure 6 . This phenomenon is explained by the open structure of wool fiber proteins induced by equation (8), which results in an increase of the number of adsorption site and, therefore, an increase in the amount of adsorption of acid dyes as well.

A great increase of $K / S$-value at higher concentration of EDA can be explained by the reaction producing free amino end group, namely, the existence of $\beta$ - $N$-(2-aminoethyl)aminoalanine (AEAAL) as shown in equation (9) and both ends do not react as equation $(8)[9,11,13]$.

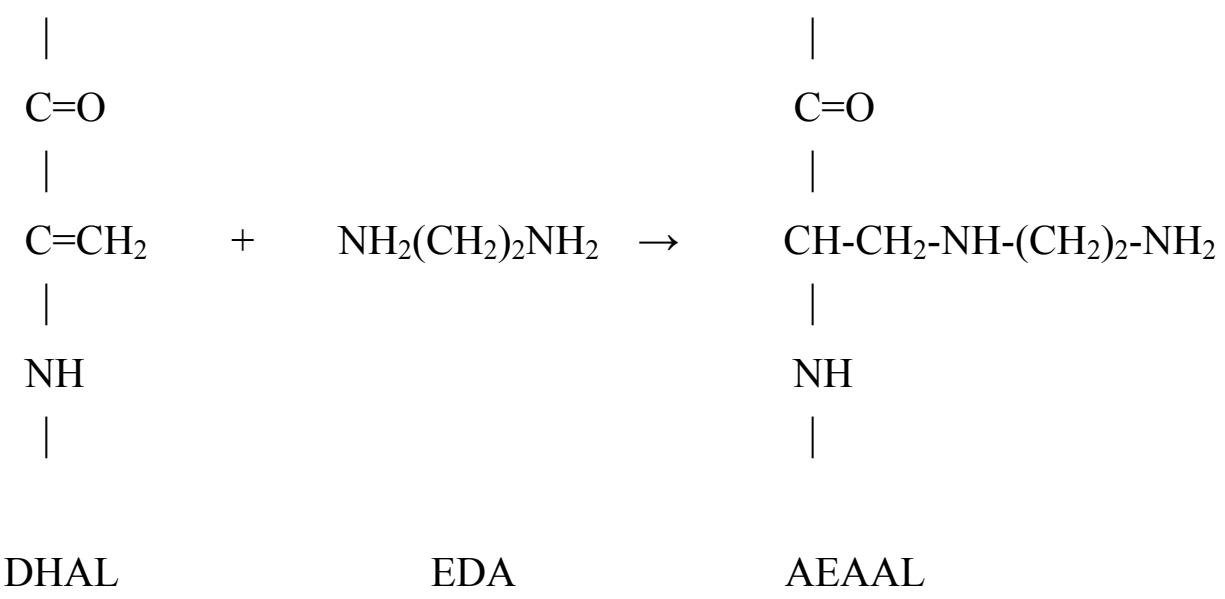

We are now studying the detailed mechanism of cross-linking from the determination of the number of intermolecular linkages introduced in wool.

\section{Conclusions}

The alkali and UB solubility tests showed that considerable amounts of the new cross-links and the amino end groups of the side chains were introduced by the treatment of wool fabric with ethylenediamine, and these resulted in excellent setability and dyeing of the fabrics. Wool fabrics can be pleat-set permanently by the treatment with EDA at a lower concentration range of 1 to $3 \%$, while flat-set successfully by a relatively higher concentration of EDA, and the setting is durable after repeated washing. No significant difference was found between the values of $L^{*}$ for untreated and treated wool in a lower range of the concentration of EDA. This means that yellowing by the treatment of EDA was very little. Tensile strength was lowered only about $2.0 \%$ by the treatment with $3 \%$ EDA. Color intensity was also improved in the case of synthetic dyes used mainly for wool fabrics and very significantly in the case of natural dyes. 


\section{References}

1. E. W. Burley, Nature, 175, 510 (1955).

2. P. T. Speakman, J. Soc. Dyers Colourists, 75, 252 (1959).

3. B. Caldwell, S. J. Leach, A. Meschers, and B. Milligan, Textile Res. J., 34, 627 (1964).

4. A. Robson, M.J. Williams, and J. W. Woodhouse, J. Textile Inst., 60, 140 (1969).

5. K. Arai, S. Naito, V.B. Dang, N. Nagasawa, and M. Hirano, J. Appl. Polym. Sci., 60, 169 (1996).

6. R. S. Asquith and P. Carthew, J. Textile Inst., 64, 10 (1973).

7. R. S. Asquith and J. D. Skinner, Textilveredlung, 5, 406 (1970).

8. K. Ziegler, Crosslinking and Self-Crosslinking in Keratin Fibers in "Chemistry of Natural Protein Fibers", (R. S. Asquith, Ed.), Plenum Press, New York, 1977.

9. K. Ziegler, J. Biol. Chem., 239, 2713 (1964).

10. K. Ziegler, Proc. $3^{\text {rd }}$ Inter. Wool Textile Res. Conf., Paris 2, 403 (1965).

11. R. S. Asquith and P. Carthew, Biochim. Biophys. Acta, 278, 8 (1972).

12. R. S. Asquith, H. D. Hanna, and M. S. Otterburn, J. Soc. Dyers \& Colourists, 91, 143 (1975).

13. J. J. Garcia-Dominguez, P. Miro, F. Reig, and S. Anguera, Applied Polymer Symp. 18, 269 (1971). 


\section{Legend}

Figure 1. A device for pleat set experiment of wool fabric: (a) the appearance of the folded sample placed between two square tiles with dimension of $10 \mathrm{~cm}$ x $10 \mathrm{~cm}$, (b) side view of the tiles with the sample folded exactly in half a size with a rectangular shape of $10 \mathrm{~cm} \mathrm{x}$ $20 \mathrm{~cm}$.

Figure 2. Relationships of concentration of EDA versus degree of set for pleated samples after treatments by different process.

Figure 3. Appearances after soaking for pleated samples treated with EDA at different concentration in \% (o.w.f.): (a) 0, (b) 1, (c) 3, (d) 6, (e) 10, (f) 20 .

Figure 4. Relationships of tensile strength and yellowing, $L^{*}$ for the samples just after setting versus concentrations of EDA.

Figure 5. Relationship of breaking elongation versus concentration of EDA.

Figure 6. Relationships of concentration of EDA versus $K / S$-value for dyeing samples with various synthetic dyes.

Figure 7. Relationships of concentration of EDA versus $K / S$-value for dyeing samples with various synthetic dyes.

Figure 8. Relationships of concentration of EDA versus $K / S$-value for dyeing samples with various natural dyes. 


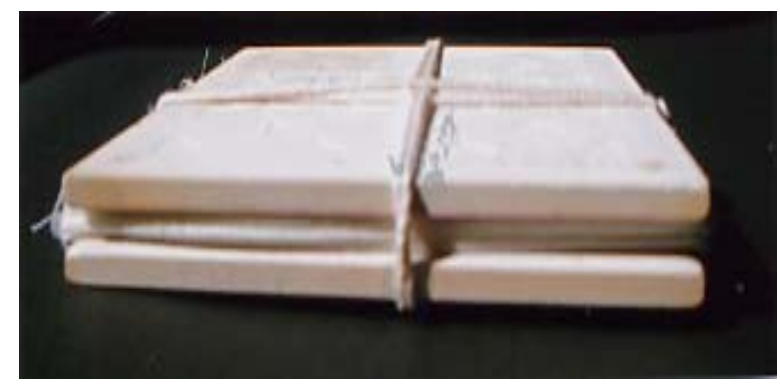

Figure 1

(a)

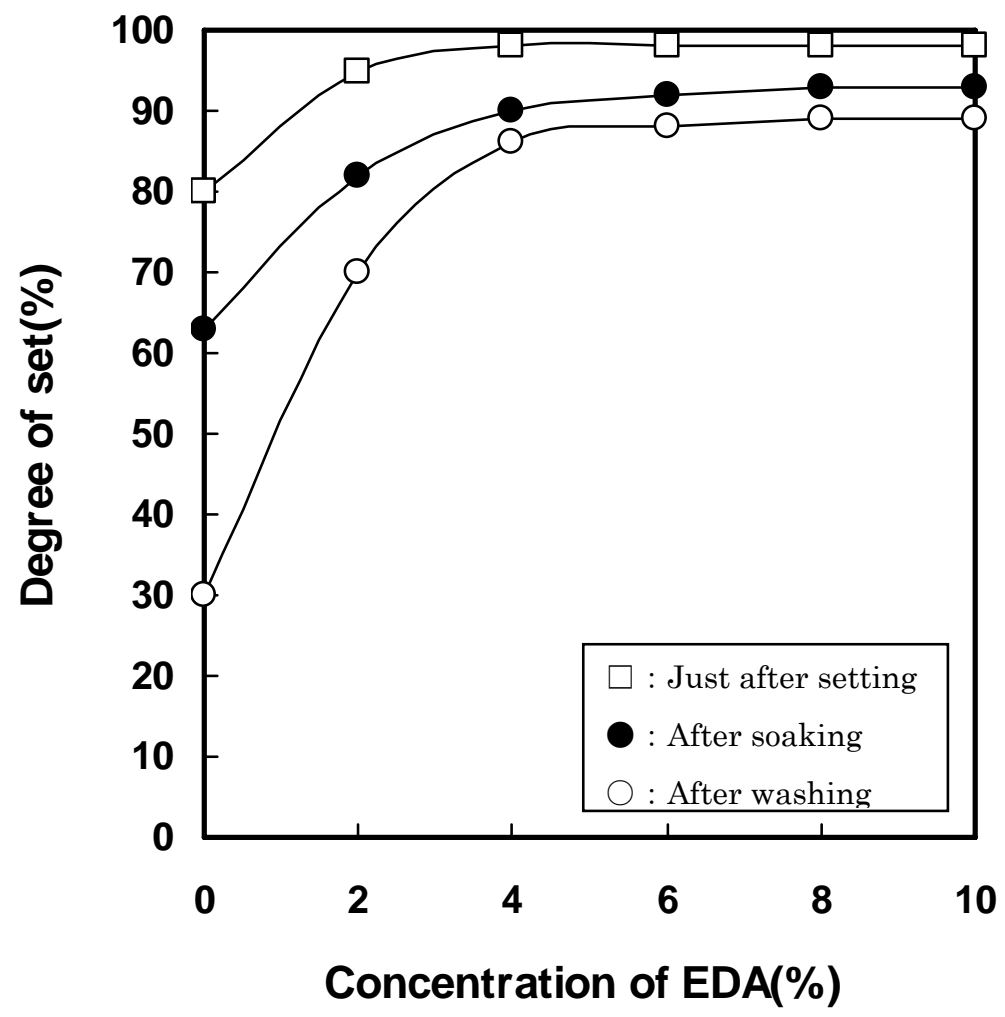

Figure 2

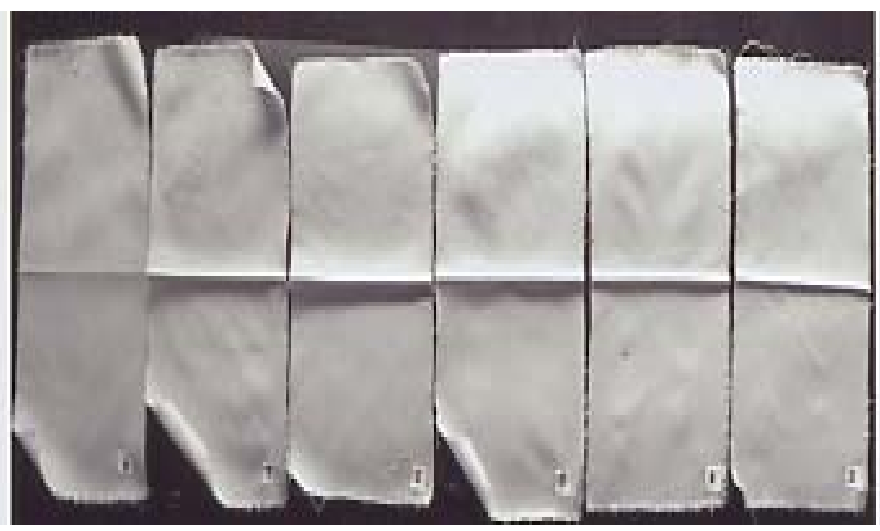
(a)
(b)
(c)
(d)
(e)
(f)

Figure 3 


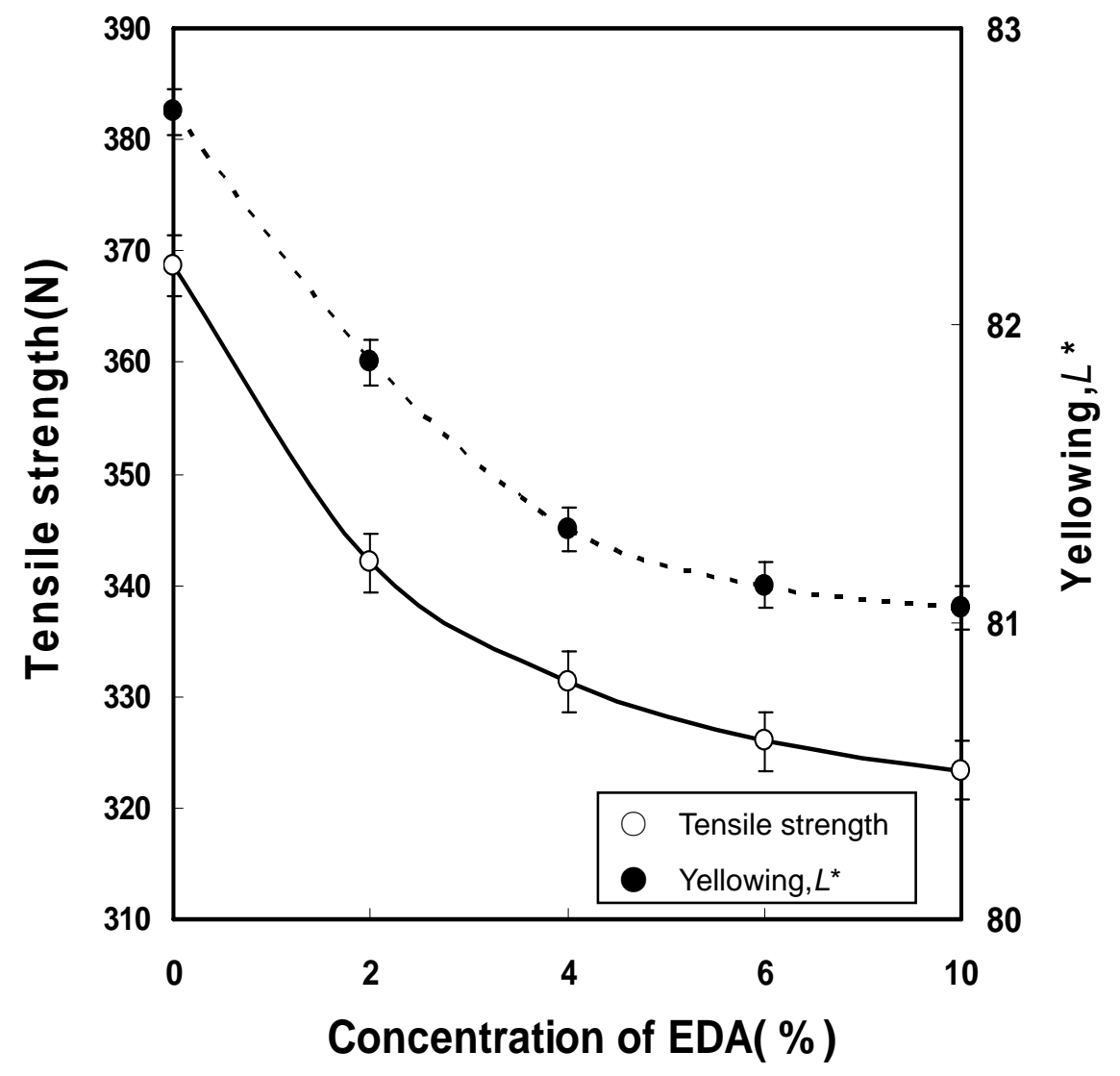

Figure 4

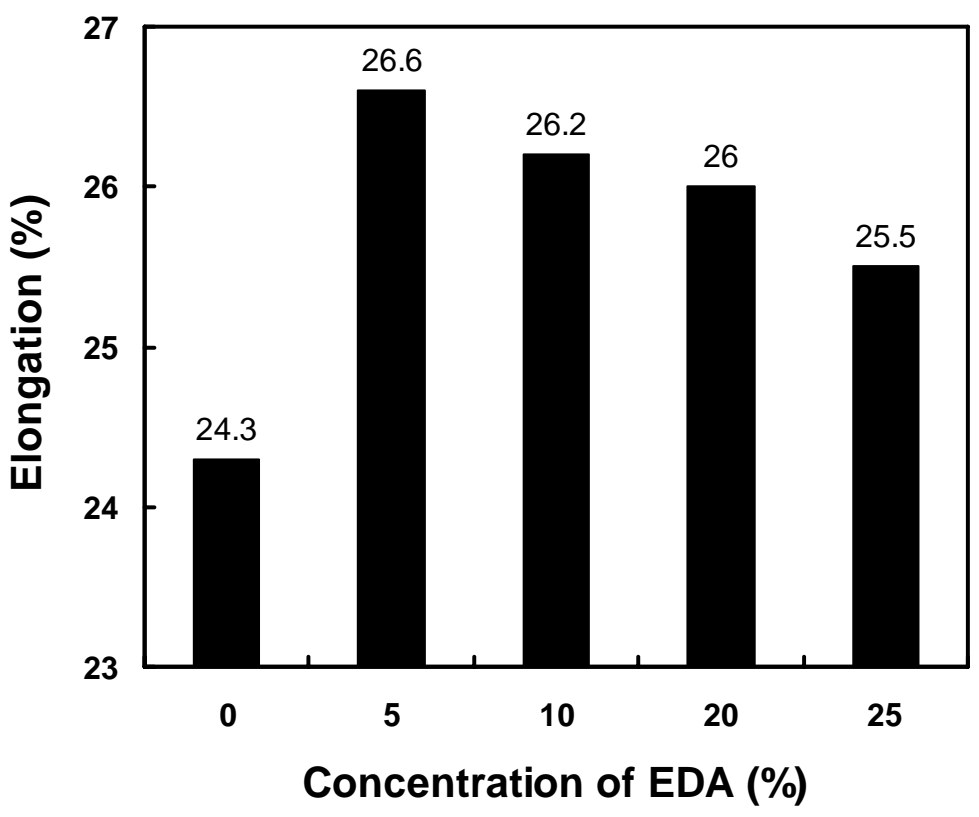

Figure 5 


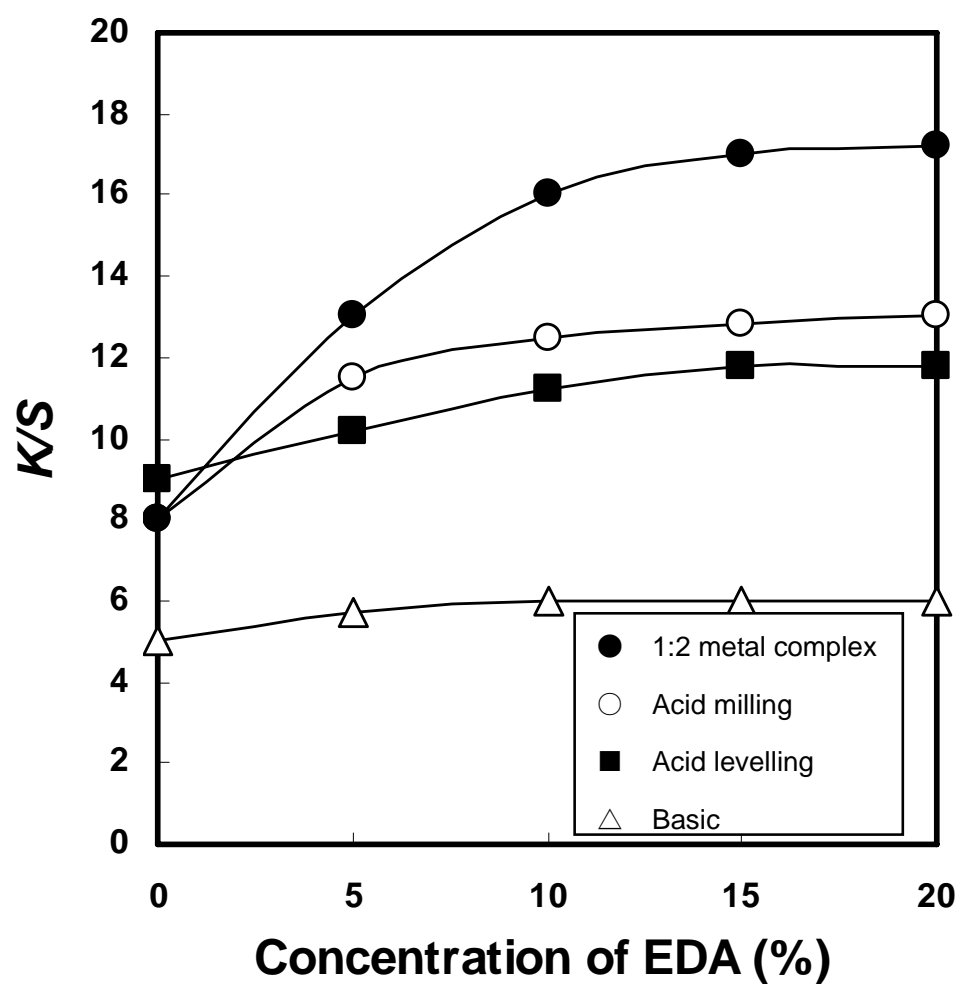

Figure 6

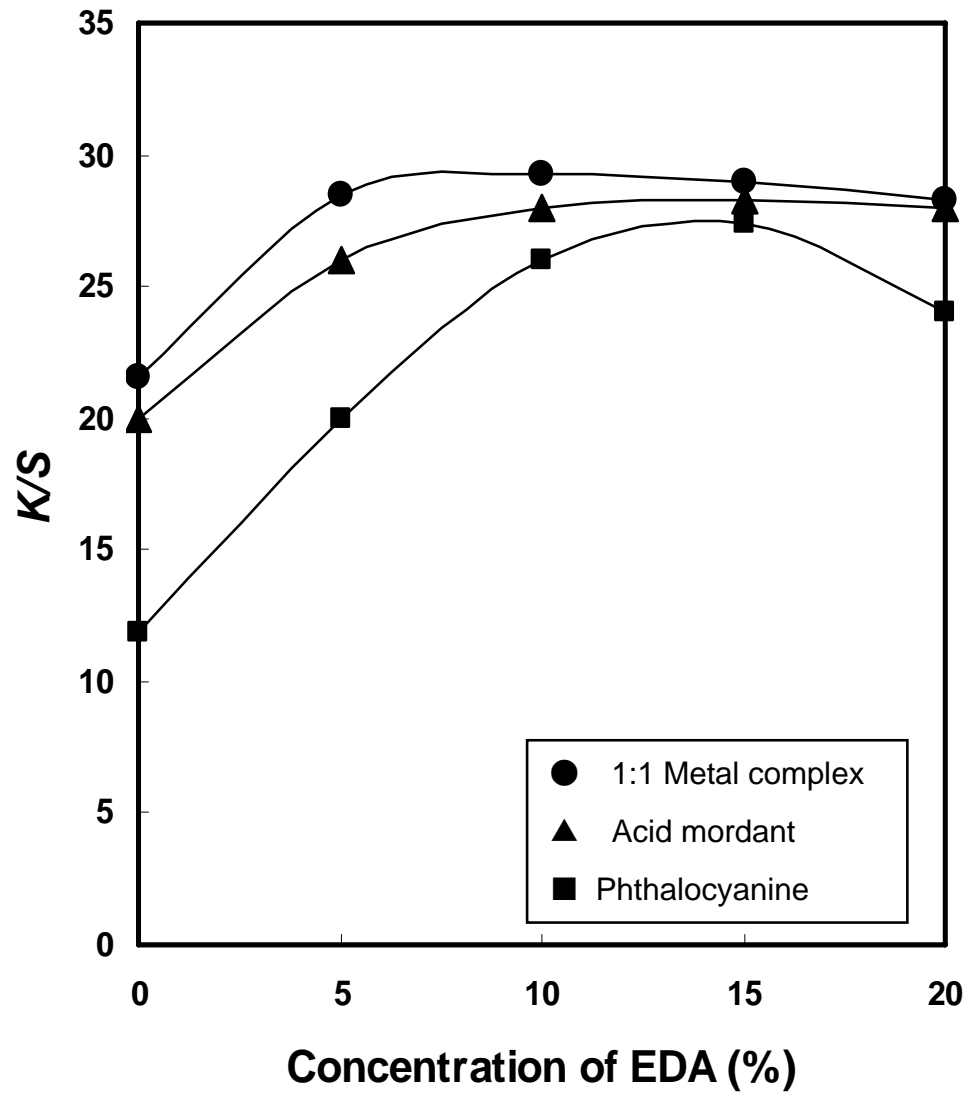

Figure 7 


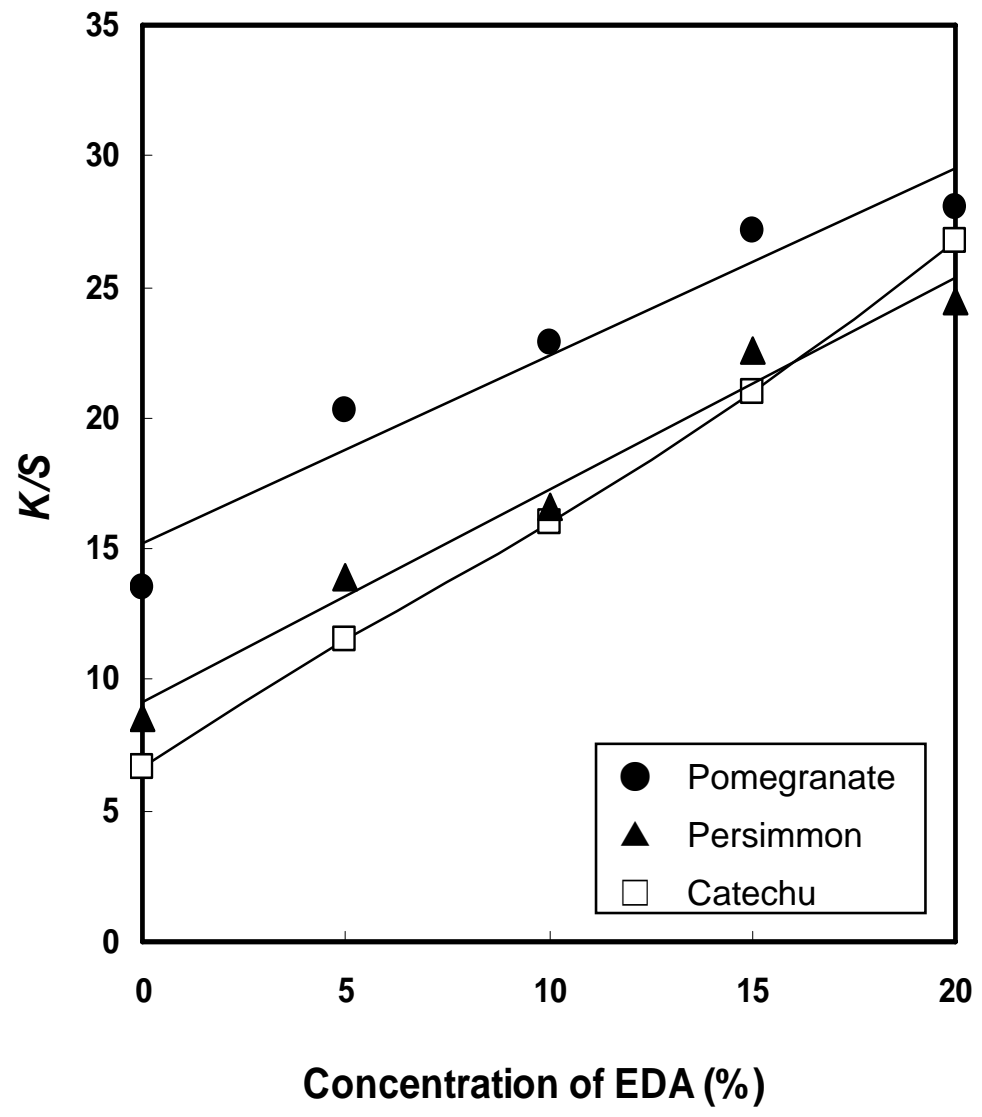

Figure 8 
Table 1. Light, potting and wet rubbing fastness of wool for various synthetic and natural dyes after setting with EDA at the concentration of $10 \%$ (o.w.f.)

\begin{tabular}{|c|c|c|c|c|c|c|c|}
\hline \multirow[t]{3}{*}{ Kinds of dye } & \multirow[t]{3}{*}{ Types } & \multicolumn{6}{|c|}{ Treated with EDA } \\
\hline & & \multicolumn{2}{|c|}{ Light } & \multicolumn{2}{|c|}{ Potting } & \multicolumn{2}{|c|}{ Rubbing } \\
\hline & & Untreated & Treated & Untreated & Treated & Untreated & Treated \\
\hline \multicolumn{8}{|l|}{ Synthetic dyes } \\
\hline C.I.Acid Red 106 & Acid Levelling & 4 & 4 & $3-4$ & $3-4$ & 5 & 5 \\
\hline C.I.Acid Green 25 & Acid Milling & 4 & 4 & 4 & $4-5$ & $4-5$ & $4-5$ \\
\hline C.I.Acid Blue 185 & Phthalocyanine & 3 & $3-4$ & $2-3$ & $3-4$ & 3 & $3-4$ \\
\hline C.I.Acid Black 207 & 1:2Metal-complex & 4 & 4 & 4 & 4 & 4 & $4-5$ \\
\hline C.I.Acid Mordant Black 11 & Acid Mordant & $3-4$ & $3-4$ & 5 & 5 & 3 & $3-4$ \\
\hline Neolan Black P & 1:1 Metl complex & 3 & 3 & 5 & 5 & 3 & $3-4$ \\
\hline C.I.Basic Violet 11 & Basic & 1 & 1 & 1 & $1-2$ & 1 & $1-2$ \\
\hline C.I.Reactive black 5 & Reactive & 4 & $4-5$ & 3 & $3-4$ & $2-3$ & $3-4$ \\
\hline \multicolumn{8}{|l|}{ Natural dyes } \\
\hline Pomegranate & & $2-3$ & 3 & 3 & $3-4$ & 3 & $3-4$ \\
\hline Myrobolans & & 3 & 4 & 3 & $3-4$ & 3 & $3-4$ \\
\hline Persimmon & & $2-3$ & $3-4$ & 3 & $3-4$ & 3 & $3-4$ \\
\hline Catechu & & $2-3$ & 3 & $2-3$ & 3 & 3 & $3-4$ \\
\hline Luc-Dye & & $2-3$ & 3 & $3-4$ & $3-4$ & $2-3$ & 3 \\
\hline
\end{tabular}

Table 2.Alkali and UB solubility of EDA-treated Wool

\begin{tabular}{lcc}
\hline & Alkali solubility & UB solubility \\
Samples & $(\%)$ & $(\%)$ \\
\hline Untreated & 17.5 & 22.0 \\
Treated with 20\% EDA & 20.4 & 10.5 \\
\hline
\end{tabular}

Table 3. Color intensity by methylene blue for EDA-treated wool

$\begin{array}{cc}\begin{array}{c}\text { Concentration of EDA } \\ \text { (\% o.w.f) }\end{array} & \text { K/S } \\ \text { Blank } & 4.7 \\ 1 & 7.5 \\ 3 & 9.8 \\ 6 & 9.9 \\ 10 & 11.8\end{array}$

